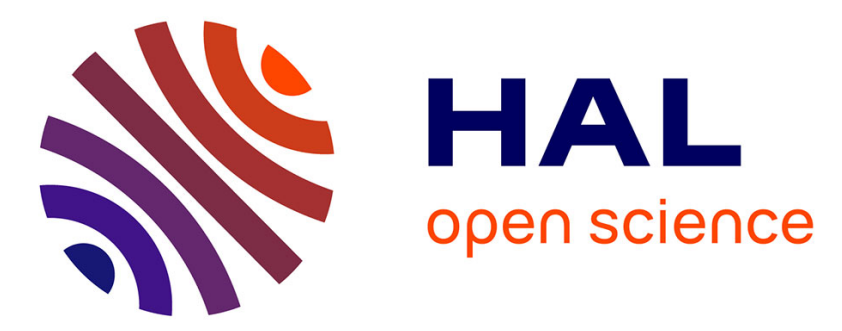

\title{
Regional variation in use of immediate breast reconstruction after mastectomy for breast cancer in England
}

R. Jeevan, D.A. Cromwell, J.P. Browne, M. Trivella, J. Pereira, C.M. Caddy, C. Sheppard, J.H.P. van Der Meulen

\section{To cite this version:}

R. Jeevan, D.A. Cromwell, J.P. Browne, M. Trivella, J. Pereira, et al.. Regional variation in use of immediate breast reconstruction after mastectomy for breast cancer in England. EJSO - European Journal of Surgical Oncology, 2010, 36 (8), pp.750. 10.1016/j.ejso.2010.06.008 • hal-00608927

\section{HAL Id: hal-00608927 \\ https://hal.science/hal-00608927}

Submitted on 16 Jul 2011

HAL is a multi-disciplinary open access archive for the deposit and dissemination of scientific research documents, whether they are published or not. The documents may come from teaching and research institutions in France or abroad, or from public or private research centers.
L'archive ouverte pluridisciplinaire HAL, est destinée au dépôt et à la diffusion de documents scientifiques de niveau recherche, publiés ou non, émanant des établissements d'enseignement et de recherche français ou étrangers, des laboratoires publics ou privés. 


\section{Accepted Manuscript}

Title: Regional variation in use of immediate breast reconstruction after mastectomy for breast cancer in England

Authors: R. Jeevan, D.A. Cromwell, J.P. Browne, M. Trivella, J. Pereira, C.M. Caddy, C. Sheppard, J.H.P. van der Meulen

PII: S0748-7983(10)00184-8

DOI: 10.1016/j.ejso.2010.06.008

Reference: $\quad$ YEJSO 2996

To appear in: European Journal of Surgical Oncology

Received Date: 12 April 2010

Accepted Date: 7 June 2010

Please cite this article as: Jeevan R, Cromwell DA, Browne JP, Trivella M, Pereira J, Caddy CM, Sheppard C, van der Meulen JHP. Regional variation in use of immediate breast reconstruction after mastectomy for breast cancer in England, European Journal of Surgical Oncology (2010), doi: 10.1016/ j.ejso.2010.06.008

This is a PDF file of an unedited manuscript that has been accepted for publication. As a service to our customers we are providing this early version of the manuscript. The manuscript will undergo copyediting, typesetting, and review of the resulting proof before it is published in its final form. Please note that during the production process errors may be discovered which could affect the content, and all legal disclaimers that apply to the journal pertain. 


\section{Regional variation in use of immediate breast reconstruction after mastectomy for breast cancer in England}

R Jeevan ${ }^{1}$, D A Cromwell ${ }^{12}$, J P Browne ${ }^{23}$, M Trivella $^{12}$, J Pereira $^{4}$, C M Caddy $^{5}, C$ Sheppard ${ }^{6}, \mathrm{~J} \mathrm{H} \mathrm{P}$ van der Meulen ${ }^{12}$

1 Clinical Effectiveness Unit, The Royal College of Surgeons of England, 35-43 Lincoln's Inn Fields, London WC2A 3PE

2 Health Services Research Unit, Department of Public Health \& Policy, London School of Hygiene \& Tropical Medicine, Keppel Street, London WC1E 7HT

3 Department of Epidemiology and Public Health, University College Cork, Cork, Ireland 4 James Paget University Hospitals NHS Foundation Trust, Lowestoft Road, Gorleston, Great Yarmouth, Norfolk, NR31 6LA

5 Sheffield Teaching Hospitals NHS Foundation Trust, Northern General Hospital, Herries Road, Sheffield, South Yorkshire, S5 7AU

6 Portsmouth Hospitals NHS Trust, Queen Alexandra Hospital, Portsmouth, Hampshire PO6 $3 L Y$

Correspondence to:

D Cromwell, Clinical Effectiveness Unit, The Royal College of Surgeons of England, 35-43 Lincoln's Inn Fields, London WC2A 3PE

Tel: $\quad$ +44(0) 2078696608

Fax: $\quad+44(0) 2078696644$

E-mail:dcromwell@rcseng.ac.uk

Manuscript length: 2058 words

Abstract length: $\quad 238$ words 


\section{ABSTRACT}

Aims: English national guidelines recommend that breast reconstruction is made available to women with breast cancer undergoing mastectomy. We examined the use of immediate reconstruction (IR) across English Cancer Networks, who are responsible for the regional organisation of cancer services and ensuring equitable access to treatment.

Methods: We analysed Hospital Episodes Statistics data for all women with breast cancer who underwent mastectomy in the English NHS between April 2006 and February 2009. IR rates were calculated for the 30 Networks. Multivariable logistic regression was used to adjust the rates for patient age, comorbidity, ethnicity and socioeconomic deprivation.

Results: Of 44837 mastectomy patients, 7375 (16.5\%) underwent IR. The IR rate was highest in women under 50 years (32.7\%) and lowest in women aged 70 years or over (1.5\%), and was lower in women with more comorbidities. Unadjusted IR rates varied from $8.4 \%$ to $31.9 \%$ among the 30 Networks $(p<0.001)$. Adjusting for their patient characteristics did not appreciably reduce Network-level variation, with adjusted IR rates still ranging from $8.0 \%$ to $29.4 \%(p<0.001)$. The risk-model also suggested that non-white women and those from more deprived areas were less likely to undergo immediate reconstruction.

Conclusions: There is substantial regional variation in immediate reconstruction use in England that is not explained by the characteristics of the local patient population. English Cancer Networks should act to reduce this variation. They should also examine why rates of reconstruction differ between particular patient groups.

Keywords: Breast Neoplasms; Mastectomy; Mammaplasty; England. 


\section{INTRODUCTION}

Each year, 38000 women are diagnosed with breast cancer in England. ${ }^{1} 40 \%$ of those treated within the National Health Service (NHS) undergo a mastectomy as part of their treatment. $^{2}$

Advances in plastic surgical techniques have made immediate breast reconstruction a safe option for most women undergoing mastectomy. ${ }^{3}$ The United Kingdom National Institute for Health and Clinical Excellence (NICE) stated in 2002 that "reconstruction should be available [to all women with breast cancer] at the initial surgical operation", ${ }^{4}$ and in 2009 that clinicians should "discuss immediate breast reconstruction with all patients who are being advised to have a mastectomy, and offer it except where significant comorbidity or (the need for) adjuvant therapy may preclude this option" ${ }^{5}$

In England, 30 regional Cancer Networks have responsibility for service delivery and resource allocation. ${ }^{6,7}$ Cancer Networks were created to overcome service fragmentation by bringing together health service commissioners and providers. A principal aim is for them to ensure patients within their regions have equitable access to high quality cancer care.

In 2009, the National Mastectomy and Breast Reconstruction Audit, a national prospective cohort study of women undergoing mastectomy with or without immediate reconstruction in England, suggested wide regional variation in immediate reconstruction rates. ${ }^{8}$ However, only three quarters of eligible patients were included, mastectomy-only patients were underreported, and regional rates were based on relatively small samples.

In this paper we used Hospital Episode Statistics (HES) ${ }^{9}$ data to derive rates of immediate breast reconstruction after mastectomy for breast cancer within the English Cancer Networks. The HES database captures all surgical procedures in NHS hospitals, and is less prone to differential reporting of mastectomy and reconstruction procedures. It also provides larger 
patient samples because it is not restricted to activity within a limited timeframe. We investigated the effect of patient characteristics on immediate reconstruction use, and the extent to which they could explain variation in rates across Networks.

\section{METHODS}

\section{Hospital Episode Statistics}

The HES database contains demographic, geographical and clinical information on all patients admitted to NHS hospitals in England. Surgical procedures are described using the UK Office for Population Censuses and Surveys classification, 4th revision (OPCS4) ${ }^{10}$ while medical conditions are described using the International Classification of Diseases, 10th revision (ICD10). ${ }^{11}$

\section{Patient population}

We extracted the HES records of all women diagnosed with invasive carcinoma of the breast (ICD10: C50) who underwent a mastectomy (OPCS4: B27) between 1 April 2006 and 28 February 2009. A woman was considered to have undergone an immediate breast reconstruction if reconstruction occurred on the same day as the mastectomy. The OPCS4 codes that defined breast reconstruction were B29 (excluding B29.5 revision), B38, B39 as well as B30.1 (insertion of prosthesis) and S48.2 (insertion of skin expander).

For each woman, we also calculated age on admission, level of comorbidity, ethnicity, and regional socioeconomic deprivation. Comorbidity was derived using the RCS Charlson comorbidity score. ${ }^{12}$ This identifies whether a women has one or more comorbidities, from a list of 22 conditions, by counting the number recorded in the index admission and in admissions during the 12 months before the index admission date. Ethnicity was coded as white, non-white, unknown or not stated. Socioeconomic deprivation was characterised using the overall combined score of the Index of Multiple Deprivation (IMD). ${ }^{13}$ IMD scores are 
calculated for 32482 geographical areas (population around 1500) and were allocated to patients based on their postcode of residence. Greater levels of deprivation are indicated by higher IMD scores.

\section{$\underline{\text { Statistical methods }}$}

Unadjusted rates of immediate reconstruction were derived as a percentage of all mastectomies and were calculated for the 30 English Cancer Networks that existed on 1 January 2008. Women were allocated to Networks by their postcode of residence. A multivariable logistic regression model was used to adjust the Network rates for age on admission, comorbidity, ethnicity, and regional deprivation. In the regression model, age and IMD score were included as continuous variables because the trend was approximately linear. For the unadjusted descriptive analyses, rates of immediate reconstruction are presented for categories of age and IMD score to aid interpretation.

The model was used to estimate the probability of a woman having an immediate reconstruction. These probabilities were then summed for women resident in a Network to calculate the predicted number of immediate reconstructions for that Network. Risk-adjusted rates of reconstruction for each Network were produced by dividing the observed number of immediate reconstructions by the predicted number, and multiplying this ratio by the national rate of reconstruction. Estimates are presented with 95\% confidence intervals $(\mathrm{Cl})$. The statistical significance of the variation in the Network-level reconstruction rates was assessed using the likelihood ratio test.

\section{RESULTS}

Between 1 April 2006 and 28 February 2009, 44837 mastectomies were performed in women with breast cancer. Their average age was 60.9 years (SD 13.9) and 6,297 (14.0\%) had one or more co-morbidities. Ethnicity was known for $87.2 \%$, of whom $94.1 \%$ were white. 
Overall, $16.5 \%$ of women had an immediate reconstruction. Unadjusted immediate reconstruction rates among the 30 English Cancer Networks varied from $8.4 \%$ to $31.9 \%$ $(p<0.001)$. Excluding the Networks with the three highest and lowest values, the rates still ranged from $11.5 \%$ to $26.9 \%$ (see Figure 1 ).

Tables 1 and 2 summarise the relationship between immediate reconstruction rates and patient characteristics. The reconstruction rate was highest in women under 50 years $(32.7 \%)$ and lowest in women aged 70 years or over (1.5\%). The rate was also lower in women with more comorbidities independent of age. After adjustment, reconstruction rates were lower in women of non-white ethnicity and also decreased with deprivation (Table 2).

However, differences in these patient characteristics between Network populations explained only a limited amount of the observed variation. There was still significant regional variation $(p<0.001)$, with adjusted rates varying from $8.0 \%$ to $29.4 \%$. After excluding the Networks with the three highest and lowest values, the adjusted rates varied from $11.7 \%$ to $25.4 \%$ (see Figure 1).

\section{DISCUSSION}

There is considerable variation in the use of immediate breast reconstruction between English Cancer Networks which persists after adjusting for patient characteristics. In addition, women who are non-white or from deprived areas are less likely to undergo immediate reconstruction. Rates of reconstruction were highest amongst women under 50 years.

\section{Limitations of the study}

There are known inaccuracies in HES coding, ${ }^{14}$ but it is unlikely that coding errors could explain the four-fold variation observed. Validation work undertaken on HES data for women having breast cancer surgery suggests that HES procedure codes are accurate, with $90-93 \%$ 
agreement with surgeon-provided data. ${ }^{15}$ To minimise the chance of including prophylactic mastectomy, we selected women with both a diagnosis code for breast cancer and a procedure code for mastectomy. We also used the full range of OPCS codes for breast reconstruction (except for revision surgery) to take account of potential differences in coding between Networks and to limit the likelihood of missing an immediate reconstruction.

The HES database does not include women diagnosed with breast cancer in independent hospitals. These women are sometimes referred back to the NHS if they decide to have immediate reconstruction. ${ }^{2}$ This may have increased NHS reconstruction rates in the Networks with relatively greater independent sector activity, such as those in and around London.

We did not have information on patient characteristics such as smoking and obesity, which are relative contraindications to reconstruction. Their prevalence is linked to deprivation ${ }^{16}$ which was included as a confounding factor in the logistic regression model. While this would only partially eliminate their effect, differences in the prevalence of these characteristics between Networks are unlikely to account for the large regional variation observed. The National Audit collected information on smoking and obesity and found that adjusting for these characteristics did not reduce the observed Network-level variation. ${ }^{8}$

\section{Sources of regional variation}

There are various sources for this regional variation. First, women's preferences for the types of breast cancer treatment will vary. In particular, preferences will depend on the information women are given about immediate reconstruction and it has been shown that clinicians are less likely to discuss reconstruction with women from deprived backgrounds. ${ }^{17,18}$

Second, post-mastectomy radiotherapy use varies across Networks. ${ }^{2}$ Radiotherapy may impair the aesthetic outcomes of immediate reconstruction and women who are expected to 
have post-operative radiotherapy may therefore prefer a delayed reconstruction. This may also apply for other adjuvant therapies.

Third, in regions with high rates of breast conserving surgery, women undergoing mastectomy would be expected to have a relatively high grade and stage. This should make them less suitable for immediate reconstruction due to the increased likelihood of post-mastectomy radiotherapy. After additional modelling (results not shown), we found that regions with high rates of breast conserving surgery also had high rates of immediate reconstruction after mastectomy. This suggests that clinicians in some regions are more inclined to offer breast conservation or immediate reconstruction than in others, irrespective of cancer stage at treatment.

Finally, there may be variation in service provision. In Networks with inadequate breast reconstruction capacity, women may be dissuaded from having an immediate reconstruction as this could delay their primary cancer treatment beyond national cancer waiting time targets. $^{21}$

\section{Findings of the National Mastectomy and Breast Reconstruction Audit}

The National Audit provides some insight into the influence of these factors. ${ }^{8}$ It reported that immediate reconstruction offer rates varied substantially between Networks and were not strongly associated with the actual rates. This was thought to reflect differences in both how the offer was communicated and to which women an offer was made.

The Audit also asked clinicians to give reasons for why women were not offered immediate reconstruction (more than one could be given). ${ }^{8}$ Anticipated radiotherapy to the chest wall and other adjuvant therapy issues were cited as a reason for around one-third of women but the proportion fluctuated from $15 \%$ to $65 \%$ between Networks. 
Availability of immediate reconstruction was give as a reason for $9 \%$ of women, although clinicians in four Networks gave this as the reason for not offering reconstruction for over $20 \%$ of women. This suggests that some regions suffer from resource constraints.

But, overall, women were most commonly deemed inappropriate due to their age, comorbidities, lifestyle factors such as smoking, and concerns about local recurrence. The NICE guidance suggests that, among the various patient characteristics, only comorbidity should legitimately preclude an offer of immediate reconstruction.

\section{Conclusion}

We have found considerable variation in the regional use of immediate breast reconstruction which persists after adjusting for patient characteristics. The variation in the HES-derived rates is comparable with the findings of the National Mastectomy and Breast Reconstruction Audit and demonstrates that the differences have not existed for a short period of time.

The analysis does not presuppose that there is an optimal rate for immediate breast reconstruction. However, the wide regional variation suggests that women with breast cancer have unequal access to immediate breast reconstruction. Cancer Networks in England need to examine local reconstructive services, both in terms of provision and how choices are offered, and act to remove barriers to its uptake.

It is likely that the issues about access to reconstruction affect breast cancer services in other countries. Our findings suggest that, when informing and counselling women diagnosed with breast cancer, clinicians should examine their local decision-making processes and ensure that, where safe and appropriate, immediate reconstruction is offered to those women undergoing mastectomy. 


\section{ACKNOWLEDGEMENTS}

We would like to thank Lynn Copley of the Clinical Effectiveness Unit for preparing the extract used in this work, and the NHS Information Centre for Health and Social Care for providing the Hospital Episode Statistics data.

\section{CONTRIBUTORS}

RJ, JB, JP, CC, CS and JvdM conceived and designed the study; MT and DC conducted the statistical analyses; RJ, DC, JB and JvdM drafted the manuscript; MT, JP, CC and CS commented on and critically revised drafts. RJ, DC, JB, MT, JP, CC, CS and JvdM all approved the final version for publication. DC is guarantor.

\section{NATIONAL MASTECTOMY AND BREAST RECONSTRUCTION AUDIT}

The Audit is managed by the National Clinical Audit Support Programme of the NHS Information Centre for Health and Social Care in partnership with the Association of Breast Surgery, the British Association of Plastic, Reconstructive and Aesthetic Surgeons, the Royal College of Nursing and the Clinical Effectiveness Unit of The Royal College of Surgeons of England.

\section{FUNDING}

The National Mastectomy and Breast Reconstruction Audit is funded by the Healthcare Commission and the Healthcare Quality Improvement Partnership.

\section{CONFLICT OF INTEREST STATEMENT}

The authors report no conflicts of interest. 


\section{REFERENCES}

1. Office for National Statistics. Cancer statistics registrations: registrations of cancer diagnosed in 2006, England. (Series MB1, No 37.) London: ONS, 2008. http://www.statistics.gov.uk/downloads/theme_health/MB1-37/MB1_37_2006.pdf

2. Jeevan R, Browne J, van der Meulen J, Caddy CM, Pereira J, Sheppard C, et al. First Annual Report of the National Mastectomy and Breast Reconstruction Audit 2008. (Ref: 18120107.) Leeds: The NHS Information Centre; 2008. http://www.ic.nhs.uk/webfiles/Services/NCASP/Cancer/new\%20web\%20documents\%20(MBR )/New\%20web\%20documents/163447\%20IC\%20MBR\%20Audit\%20Final.pdf

3. Malata CM, McIntosh SA, Purushotham AD. Immediate breast reconstruction after mastectomy for cancer. Br J Surg 2000; 87:1455-72.

4. National Institute for Clinical Excellence. Guidance on cancer services. Improving outcomes in breast cancer - manual update. London: NICE, 2002. http://www.nice.org.uk/nicemedia/pdf/Improving_outcomes_breastcancer_manual.pdf

5. National Institute for Health and Clinical Excellence. Early and locally advanced breast cancer: diagnosis and treatment. (Clinical guideline 80.) London: NICE, 2009. http://www.nice.org.uk/nicemedia/pdf/CG80NICEGuideline.pdf

6. A policy framework for commissioning cancer services: A report by the Expert Advisory Group on Cancer to the Chief Medical Officers of England and Wales. London: The Expert Advisory Group on Cancer to the Chief Medical Officers of England and Wales, 1995. http://www.dh.gov.uk/prod_consum_dh/groups/dh_digitalassets/@dh/@en/documents/digitala sset/dh_4014366.pdf 
7. The NHS Cancer plan: a plan for investment, a plan for reform. London: Department of Health, 2000.

http://www.dh.gov.uk/prod_consum_dh/groups/dh_digitalassets/@dh/@en/documents/digitala sset/dh_4014513.pdf

8. Jeevan R, Cromwell D, Browne J, van der Meulen J, Caddy CM, Pereira J, Sheppard C, et al. Second Annual Report of the National Mastectomy and Breast Reconstruction Audit 2009. Leeds: The NHS Information Centre, 2008.

http://www.ic.nhs.uk/services/national-clinical-audit-support-programme-ncasp/auditreports/mastectomy-and-breast-reconstruction

9. The NHS Information Centre for health and social care. Hospital Episode Statistics (HES). Leeds: The NHS Information Centre, 2009.

http://www.dh.gov.uk/en/Publicationsandstatistics/Statistics/HospitalEpisodeStatistics/index.ht $\mathrm{m}$

10. Office of Population Censuses and Surveys. Tabular List of the Classification of Surgical Operations and Procedures: Fourth Revision Consolidated Version. (ISBN 0116912952.) London: HMSO, 1990.

11. World Health Organisation. International Classification of Diseases and Related Health Problems, Tenth Revision. (ISBN 9241544198.) Geneva, Switzerland: WHO, 1992.

12. Armitage JN, van der Meulen $\mathrm{JH}$; on behalf of the Royal College of Surgeons Co-morbidity Consensus Group. Identifying co-morbidity in surgical patients using administrative data with the Royal College of Surgeons Charlson Score. Br J Surg. 2010 Mar 19. [Epub ahead of print] 
13. Noble M, Wright G, Dibben C, Smith GAN, McLennan D, Anttila C, et al. The English Indices of Deprivation 2004 (revised). (ODPM Licence No: 100018986.) London: HMSO, 2004.

http://www.communities.gov.uk/documents/communities/pdf/131209.pdf

14. PbR data Assurance Framework 2007/08. Findings from the first year of the national clinical coding audit programme. London: Audit Commission, 2008.

15. West Midlands Cancer Intelligence Unit. Breast Cancer Clinical Outcome Measures Project Newsletter: Issue 5 August 2009. Birmingham: WMCIU, 2009.

http://www.wmpho.org.uk/wmciu/documents/BCCOM_newsletts/BCCOM\%20NewsletterAugu st09v1.4.pdf

16. Adams RJ, Howard N, Tucker G, Appleton S, Taylor AW, Chittleborough C, et al. Effects of area deprivation on health risks and outcomes: a multilevel, cross-sectional, Australian population study. Int J Public Health. 2009;54(3):183-92.

17. Polacek GN, Ramos MC, Ferrer RL. Breast cancer disparities and decision-making among U.S women. Patient Educ Couns. 2007;65(2):158-65.

18. Greenberg CC, Schneider EC, Lipsitz SR, Ko CY, Malin JL, Epstein AM, et al. Do variations in provider discussions explain socioeconomic disparities in postmastectomy breast reconstruction? J Am Coll Surg. 2008;206(4):605-15.

19. Alderman AK, Hawley ST, Waljee J, Mujahid M, Morrow M, Katz SJ. Correlates of referral practices of general surgeons to plastic surgeons for mastectomy reconstruction. Cancer $2007 ; 109(9): 1715-20$. 
20. Callaghan CJ, Couto E, Kerin MJ, Rainsbury RM, George WD, Purushotham AD. Breast reconstruction in the United Kingdom and Ireland. Br J Surg. 2002;89(3):335-40.

21. Department of Health. Shared accountability for Cancer Waiting Times - Monitoring the two month target from GP referral to treatment for Breast Cancer - England Quarter 2 2008/09. London: DH, 2008.

http://www.performance.doh.gov.uk/cancerwaits/2008/q2/part5.html 
Table 1. Unadjusted rates of immediate reconstruction among women with breast cancer undergoing mastectomy in English NHS trusts between 2006 and 2009.

\begin{tabular}{|c|c|c|c|c|}
\hline & & $\begin{array}{l}\text { Number of } \\
\text { women }\end{array}$ & $\begin{array}{l}\text { Percentage } \\
\text { in each } \\
\text { group / \% }\end{array}$ & $\begin{array}{l}\text { IR rate in each } \\
\text { group } / \%\end{array}$ \\
\hline All women & & 44837 & - & 16.4 \\
\hline \multirow[t]{6}{*}{ Age (years) } & Under 40 & 2579 & 5.8 & 37.9 \\
\hline & 40 to 49 & 7966 & 17.8 & 31.0 \\
\hline & 50 to 59 & 10407 & 23.2 & 24.4 \\
\hline & 60 to 69 & 10867 & 24.2 & 11.0 \\
\hline & 70 to 79 & 8410 & 18.8 & 2.1 \\
\hline & 80 or over & 4608 & 10.3 & 0 \\
\hline Number of & 0 & 38540 & 86.0 & 17.8 \\
\hline \multirow[t]{2}{*}{ Comorbidities } & 1 & 5550 & 12.4 & 8.9 \\
\hline & 2 or more & 747 & 1.7 & 3.1 \\
\hline \multirow[t]{4}{*}{ Ethnicity } & White & 36778 & 82.0 & 16.2 \\
\hline & Non-white & 2309 & 5.2 & 19.2 \\
\hline & Unknown & 1037 & 2.3 & 17.4 \\
\hline & Not stated & 4713 & 10.5 & 16.5 \\
\hline Index of & 1 (Least deprived) & 9467 & 21.1 & 19.8 \\
\hline Multiple & 2 & 9948 & 22.2 & 17.7 \\
\hline \multirow[t]{3}{*}{ Deprivation } & 3 & 9562 & 21.3 & 15.6 \\
\hline & 4 & 8449 & 18.8 & 14.7 \\
\hline & 5 (Most deprived) & 7411 & 16.5 & 13.6 \\
\hline
\end{tabular}


Table 2. Relative risk of immediate reconstruction among women with breast cancer undergoing mastectomy in English NHS trusts between 2006 and 2009.

\begin{tabular}{|c|c|c|c|c|c|}
\hline & & $\begin{array}{l}\text { Unadjusted } \\
\text { odds ratio }\end{array}$ & $\begin{array}{l}\text { Adjusted } \\
\text { odds ratio }\end{array}$ & $95 \% \mathrm{Cl}$ & $p$-value \\
\hline Age & $\begin{array}{l}\text { Per } 10 \text { year } \\
\text { increase }\end{array}$ & 0.47 & 0.47 & $0.46-0.48$ & $<0.001$ \\
\hline Number of & 0 & 1 & 1 & & \\
\hline \multirow[t]{2}{*}{ Comorbidities } & 1 & 0.45 & 0.67 & $0.61-0.75$ & $<0.001$ \\
\hline & 2 or more & 0.15 & 0.35 & $0.23-0.53$ & $<0.001$ \\
\hline \multirow[t]{4}{*}{ Ethnicity } & White & 1 & 1 & & \\
\hline & Non-white & 1.23 & 0.86 & $0.77-0.97$ & 0.01 \\
\hline & Unknown & 1.08 & 1.08 & $0.90-1.28$ & 0.41 \\
\hline & Not stated & 1.02 & 0.98 & $0.90-1.06$ & 0.57 \\
\hline $\begin{array}{l}\text { Index of Multiple } \\
\text { Deprivation }\end{array}$ & $\begin{array}{l}\text { Per } 10 \text { unit } \\
\text { increase }\end{array}$ & 0.89 & 0.86 & $0.85-0.88$ & $<0.001$ \\
\hline
\end{tabular}


Figure 1. Unadjusted and adjusted rates of immediate reconstruction for women with breast cancer undergoing mastectomy across the 30 English Cancer Networks. Each value is presented with its $95 \%$ confidence interval.

Surrey, West Sussex \& Hampshir

South East London

Essex

South West London

Sussex

Anglia

West London

Humber \& Yorkshire Coast

3 Counties

North East London

Central South Coast

North London

Avon, Somerset \& Wiltshire

Mount Vernon

Kent \& Medway

Merseyside \& Cheshire

Greater Manchester and Cheshire

Greater Midlands

Yorkshire Cancer Network

Thames Valley

Dorset

Arden

Lancashire and South Cumbria

Peninsula

Mid Trent

North Trent

Pan Birmingham

Derby / Burton

Leicestershire, Northamptonshire and Rutland

North of England

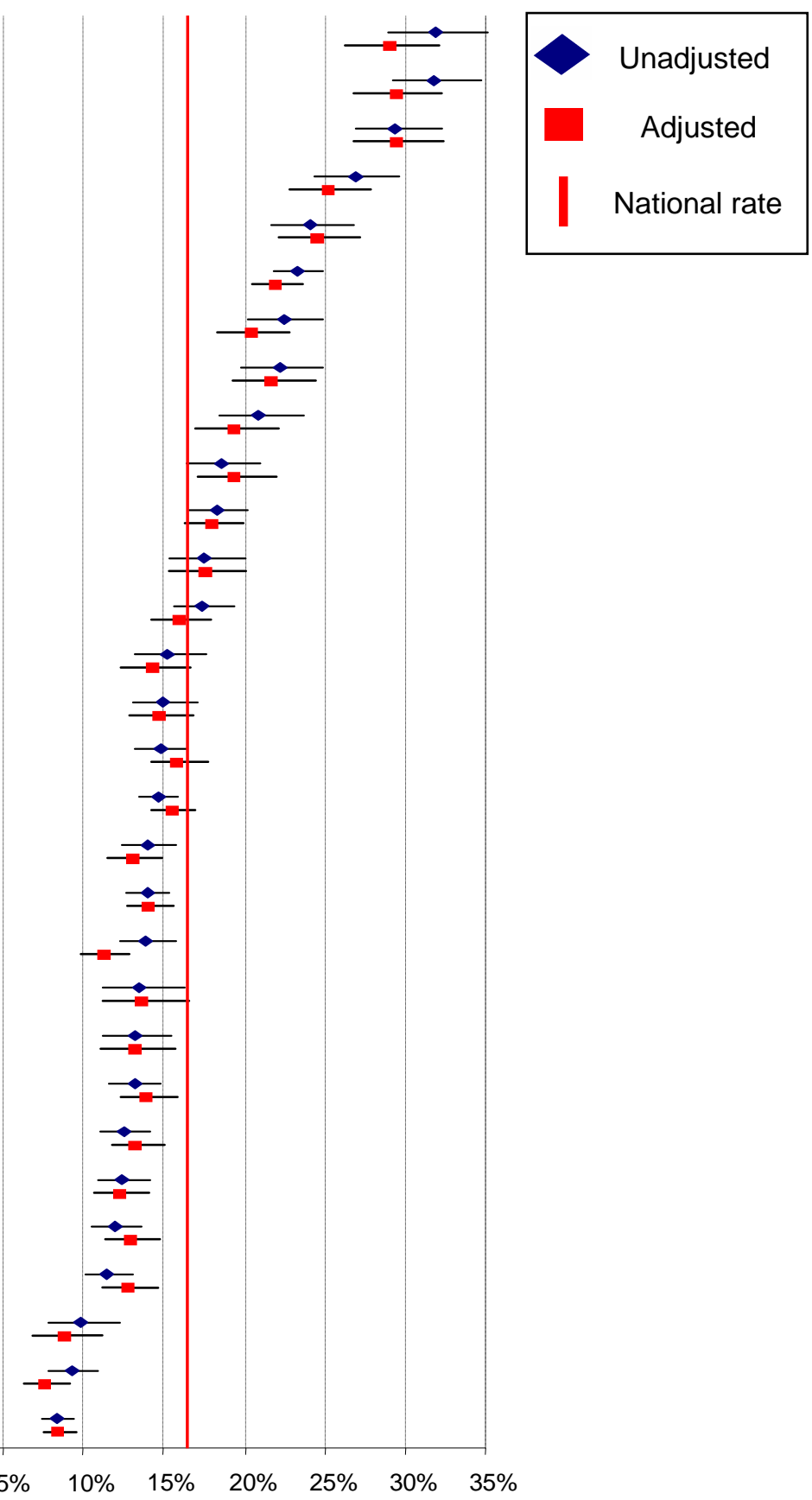

